\title{
A Copper Protein and a Cytochrome Bind at the Same Site on Bacterial Cytochrome $c$ Peroxidase ${ }^{\dagger}$
}

\author{
Sofia R. Pauleta, ${ }^{\ddagger}, \S$ Alan Cooper,${ }^{\perp}$ Margaret Nutley, ${ }^{\perp}$ Neil Errington, ${ }^{\|}$Stephen Harding,,$"$ Francoise Guerlesquin,,${ }^{\nabla}$ \\ Celia F. Goodhew, ${ }^{\ddagger}$ Isabel Moura,${ }^{\S}$ Jose J. G. Moura, ${ }^{\S}$ and Graham W. Pettigrew ${ }^{\ddagger}$ \\ Veterinary Biomedical Sciences, Royal (Dick) School of Veterinary Studies, University of Edinburgh, \\ Summerhall, Edinburgh EH9 1QH, U.K., Department of Chemistry, University of Glasgow, Glasgow G12 8QQ, U.K., \\ Centre for Macromolecular Hydrodynamics, University of Nottingham, Sutton Bonington, Nottingham LE12 5 RD, U.K., \\ Unite de Bioenergetique et Ingenierie des Proteines, IBSM-CNRS, 31 chemin Joseph Aiguier, \\ 13402 Marseilles cedex 20, France, Requimte, Departamento de Quimica, CQFB, Universidade Nova de Lisboa, \\ 2829-516 Monte de Caparica, Portugal
}

Received July 5, 2004; Revised Manuscript Received September 9, 2004

\begin{abstract}
Pseudoazurin binds at a single site on cytochrome $c$ peroxidase from Paracoccus pantotrophus with a $K_{\mathrm{d}}$ of $16.4 \mu \mathrm{M}$ at $25^{\circ} \mathrm{C}, \mathrm{pH} 6.0$, in an endothermic reaction that is driven by a large entropy change. Sedimentation velocity experiments confirmed the presence of a single site, although results at higher pseudoazurin concentrations are complicated by the dimerization of the protein. Microcalorimetry, ultracentrifugation, and ${ }^{1} \mathrm{H}$ NMR spectroscopy studies in which cytochrome $c 550$, pseudoazurin, and cytochrome $c$ peroxidase were all present could be modeled using a competitive binding algorithm. Molecular docking simulation of the binding of pseudoazurin to the peroxidase in combination with the chemical shift perturbation pattern for pseudoazurin in the presence of the peroxidase revealed a group of solutions that were situated close to the electron-transferring heme with $\mathrm{Cu}-\mathrm{Fe}$ distances of about $14 \AA$. This is consistent with the results of ${ }^{1} \mathrm{H}$ NMR spectroscopy, which showed that pseudoazurin binds closely enough to the electron-transferring heme of the peroxidase to perturb its set of heme methyl resonances. We conclude that cytochrome $c 550$ and pseudoazurin bind at the same site on the cytochrome $c$ peroxidase and that the pair of electrons required to restore the enzyme to its active state after turnover are delivered one-by-one to the electron-transferring heme.
\end{abstract}

Electron-transfer processes have to be both fast and specific. Specificity requires buried redox centers and tight binding with accurate recognition of surfaces, but speed requires exposed redox centers and binding that is loose enough to allow prompt dissociation of the product complex. Reconciliation of the requirements for specificity and speed can be achieved in a model involving fluid and transient encounter complexes. Features of this model include electrostatic preorientation of redox donors and lateral search within transient complexes for favorable electron conduction routes to largely or completely buried redox centers (1). The transient nature of such complexes means that cocrystallography is often unsuccessful and other means have to be employed to characterize them.

The eukaryotic cytochrome $c$ peroxidase from yeast has become a model system for the study of biological electron transfer (2). Bacterial cytochrome $c$ peroxidases are distinct

\footnotetext{
This work was supported with a PhD grant from Fundação para a Ciência e Tecnologia (No. BD/18297/98) to S.R.P. and a BBSRC grant to G.W.P.

* Corresponding author. Tel: 44-131-650-6135. Fax: 44-131-1656576. E-mail: G.Pettigrew@ed.ac.uk.

$\doteqdot$ University of Edinburgh.

$\S$ Universidade Nova de Lisboa.

${ }^{\perp}$ University of Glasgow.

"University of Nottingham.

$\nabla$ IBSM-CNRS
}

in structure and mechanism and afford a parallel model system for investigation (3-5). The active form of bacterial cytochrome $c$ peroxidase is a mixed valence state in which an electron-transferring heme contains $\mathrm{Fe}(\mathrm{II})$ and a peroxidatic heme contains $\mathrm{Fe}$ (III) $(6,7)$. The enzyme supplies two electrons for the reduction of the substrate, hydrogen peroxide, to water, and thus two electrons are required to restore the active form of the enzyme after turnover. We have shown that the cytochrome $c$ peroxidase from Paracoccus pantotrophus can bind cytochrome $c 550$ (the physiological electron donor) at a site close to the electrontransferring heme but that horse cytochrome $c$ (a nonphysiological electron donor) binds preferentially at a different site $(8,9)$. In addition, we have found that the peroxidase can accommodate both horse cytochrome $c$ and cytochrome $c 550$ in a ternary complex (10). Although this is a nonphysiological complex, it does raise the possibility that the enzyme is designed to accommodate two redox donors at the same time.

Pseudoazurin is a small copper protein that has been shown to substitute for cytochrome $c 550$ in the reduction of the enzyme nitrite reductase (cytochrome $c d_{1}$ ) in Paracoccus pantotrophus LMD 82.5(11). We have shown that the pseudoazurin gene is present and is identical in the closely related organism Paracoccus pantotrophus LMD 52.44, which we have used for our studies on cytochrome $c$ 
peroxidase (1). Cytochrome $c$ peroxidase has comparable activities when cytochrome $c 550$ or pseudoazurin are used as electron donors (1). Both these proteins have pronounced charge asymmetry with a ring of lysines surrounding a relatively hydrophobic front face at the center of which is the proposed electron-transfer site. In the case of cytochrome $c 550$, this electron-transfer site is the exposed heme edge, while for pseudoazurin it is a histidine coordinating the buried copper. In both cases, these electron-transfer sites are the point at which large dipole moments exit the protein surface. This is consistent with a role for the dipole moment in preorientation during encounter with the negative electrostatic field of the cytochrome $c$ peroxidase $(1,12)$. In this paper, we investigate whether the pseudoazurin and the cytochrome $c 550$ bind at different sites and simultaneously or whether they compete for the same site.

\section{MATERIALS AND METHODS}

Source of the Proteins. Cytochrome $c$ peroxidase was purified from Paracoccus pantotrophus (LMD 52.44) as described by Goodhew et al. (13). Pseudoazurin was purified either from $P$. pantotrophus LMD 82.5 or the recombinant pseudoazurin gene from $P$. pantotrophus LMD 52.44 was expressed in Escherichia coli (1). These two sources gave identical proteins (1). Enzyme, cytochrome, and pseudoazurin concentrations were determined using extinction coefficients for the oxidized forms of $250 \mathrm{mM}^{-1} \mathrm{~cm}^{-1}$ (cytochrome $c$ peroxidase, $409 \mathrm{~nm}$ ), $108 \mathrm{mM}^{-1} \mathrm{~cm}^{-1}$ (cytochrome $c 550$, $410 \mathrm{~nm}$ ), and $3 \mathrm{mM}^{-1} \mathrm{~cm}^{-1}$ (pseudoazurin, $590 \mathrm{~nm}$ ). The latter figure was reevaluated in ref 1 .

Analytical Ultracentrifugation. Partial specific volumes of the proteins were calculated from the amino acid composition and are $0.7318 \mathrm{~mL} / \mathrm{g}$ (cytochrome $c$ peroxidase), $0.735 \mathrm{~mL} / \mathrm{g}$ (cytochrome $c 550$ ), and $0.7382 \mathrm{~mL} / \mathrm{g}$ (pseudoazurin) using SEDNTERP (based on ref 14). Protein solutions were equilibrated with the appropriate buffer by molecular exclusion chromatography on Sephadex G25. The Beckman Optima XL-A or XL-I (Beckman, Palo Alto, CA) analytical ultracentrifuges, equipped with scanning absorption optics, were used in all the sedimentation velocity experiments at $45000 \mathrm{rpm}, 25{ }^{\circ} \mathrm{C}$. Sedimentation coefficients (s) were obtained by scanning at 500 or $530 \mathrm{~nm}$ depending on the protein concentration in the cell. The extinction coefficients of the cytochrome $c$ peroxidase at these wavelengths are 17.2 and $20 \mathrm{mM}^{-1} \mathrm{~cm}^{-1}$, respectively. Occasionally scans were performed at $590 \mathrm{~nm}$ to monitor the pseudoazurin, but the low extinction coefficient $\left(3 \mathrm{mM}^{-1} \mathrm{~cm}^{-1}\right)$ means that profiles are noisy. The DCDT+ program of Philo (15) was used to analyze groups of boundaries to derive sedimentation coefficients. Sedimentation and diffusion coefficients were corrected to standard solvent conditions (the viscosity and, for the sedimentation coefficient, the density of water at $20^{\circ} \mathrm{C}$ ) using the SEDNTERP program. Estimates of $M_{\mathrm{r}}$ for the complex were obtained from the experimentally determined sedimentation coefficients using the relationship (see Results section)

$$
s_{\text {complex }} / s_{\text {enzyme }}=\left(M_{\mathrm{r}, \text { complex }} / M_{\mathrm{r}, \text { enzyme }}\right)^{0.57}
$$

The derived values of $M_{\mathrm{r}, \text { complex }}$ were used to obtain the added $M_{\mathrm{r}}$ due to the bound pseudoazurin, and this was expressed as a proportion of 26810 , which is the added $M_{\mathrm{r}}$ that would correspond to a pseudoazurin binding to each monomer of the dimeric protein.

Microcalorimetry. Protein solutions were equilibrated with the appropriate buffer by molecular exclusion chromatography on Sephadex G-25. The titrant solution was then concentrated by centrifugation above a Vivaspin membrane $\left(M_{\mathrm{r}}\right.$ cutoff 5000). Protein solutions were degassed, and the target cytochrome $c$ peroxidase was placed in the sample chamber of the VP-ITC microcalorimeter (Microcal). The syringe was filled with a solution of the probe protein, and successive injections of $10 \mu \mathrm{L}$ were delivered into the stirred chamber (after an initial injection of $1 \mu \mathrm{L}$ ). The duration of the additions was $20 \mathrm{~s}$, and they were $180 \mathrm{~s}$ apart. The instrument records the heat evolved or absorbed in the sample chamber by adjusting a heating circuit to maintain a constant temperature, and the data are analyzed with Microcal Origin software, which fits on the basis of iteration within a Marquandt routine. Data were fitted using the one-set-ofsites model. The value of $K_{\mathrm{d}}$ was used to calculate the standard Gibbs free energy change $\left(\Delta G^{\circ}\right)$. The standard free energy change and the standard enthalpy change were used to calculate a standard entropy change $\left(\Delta S^{\circ}\right)$.

${ }^{l} H$ NMR Spectroscopy. (i) Protein Samples. The protein samples (cytochrome $c$ peroxidase, pseudoazurin, and cytochrome c550) were desalted into $10 \mathrm{mM}$ Hepes, ${ }^{1} 2 \mathrm{mM}$ $\mathrm{CaCl}_{2}, \mathrm{pH} 7.5$, using a Sephadex G25 column, and concentrated above a Vivaspin membrane (with $M_{\mathrm{r}}$ cutoff 5000).

The binary titrations were carried out using a solution of $0.2 \mathrm{mM}$ cytochrome $c$ peroxidase in $10 \mathrm{mM}$ Hepes, $2 \mathrm{mM}$ $\mathrm{CaCl}_{2}, \mathrm{pH} 7.5$, in $10 \% \mathrm{D}_{2} \mathrm{O}$ with increasing amounts of pseudoazurin or cytochrome $c_{550}$. In the competition experiments, pseudoazurin or cytochrome $c_{550}$ were added to a solution containing $0.2 \mathrm{mM}$ peroxidase and either $0.2 \mathrm{mM}$ cytochrome $c 550$ or $0.2 \mathrm{mM}$ pseudoazurin, respectively, until a 1.5 molar ratio was achieved.

(ii) Data Acquisition. 1D NMR spectra were recorded on a Bruker Avance DRX 500 spectrometer at $299 \mathrm{~K}$ with a spectral width of $200 \mathrm{ppm}$ for 32000 data points and 1024 scans accumulated. NMR spectra were obtained using presaturation of water and processed using xwinnmr provided by Bruker. The chemical shifts were referenced to the $\mathrm{H}_{2} \mathrm{O}$ resonance (4.76 ppm at $299 \mathrm{~K}$ ).

(iii) Data Analysis of Binding in the Presence of Two Protein Ligands. In the case of the titrations in which both cytochrome $c 550$ and pseudoazurin were present with the peroxidase, it was considered that the chemical shift variation for a mixture of two complexes (PA and $\mathrm{PB}$ ) is given by

$$
\Delta \delta_{\mathrm{obs}}=\Delta \delta_{\max , \mathrm{A}} x_{\mathrm{PA}}+\Delta \delta_{\max , \mathrm{B}} x_{\mathrm{PB}}
$$

where $\Delta \delta_{\text {max,A }}$ and $\Delta \delta_{\text {max }, \mathrm{B}}$ are the maximum chemical shift variation for the complex formed between $\mathrm{PA}$ and $\mathrm{PB}$, respectively, and $x_{\mathrm{PA}}$ and $x_{\mathrm{PB}}$ are the molar ratio for bound $\mathrm{PA}$ and $\mathrm{PB}$, respectively.

On one hand, if there is competition, increasing the amount of $\mathrm{A}$ will displace $\mathrm{B}$; thus, the molar ratio of $\mathrm{PB}$ will decrease, while the molar ratio of PA increases, and the chemical shift variation observed will vary according to these changes. On the other hand, if there are two different binding

\footnotetext{
${ }^{1}$ Abbreviations: Mes, 2-[N-morpholino]ethanesulfonic acid; Hepes, $N$ [2-hydroxyethyl]piperazine- $N^{\prime}$-[2-ethanesulfonic acid]; UV, ultraviolet.
} 
sites and the binding of one protein does not affect the binding of the other, the chemical shift variation will be given by the same eq 1 , but the molar ratio of one (PA) is unchanged, while the molar ratio of the other increases (PB), and there is a cumulative effect in terms of chemical shift variation for the two proteins.

Analysis of Competitive Binding. For proteins A and B binding to protein $\mathrm{P}$ at a single site with $K_{\mathrm{d}, \mathrm{A}}=[\mathrm{P}][\mathrm{A}] /[\mathrm{PA}]$ and $K_{\mathrm{d}, \mathrm{B}}=[\mathrm{P}][\mathrm{B}] /[\mathrm{PB}]$, Wang $(16)$ has shown that the cubic equation describing this binding can be solved to give

$$
\begin{aligned}
& {[\mathrm{PA}]=\frac{[\mathrm{A}]_{0}\left(2 \sqrt{\left(a^{2}-3 b\right)} \cos (\theta / 3)-a\right)}{3 K_{\mathrm{d}, \mathrm{A}}+\left(\sqrt{\left(a^{2}-3 b\right)} \cos (\theta / 3)-a\right)}} \\
& {[\mathrm{PB}]=\frac{[\mathrm{B}]_{0}\left(2 \sqrt{\left(a^{2}-3 b\right)} \cos (\theta / 3)-a\right)}{3 K_{\mathrm{d}, \mathrm{B}}+\left(\sqrt{\left(a^{2}-3 b\right)} \cos (\theta / 3)-a\right)}}
\end{aligned}
$$

where

$$
\begin{gathered}
\theta=\arccos \frac{-2 a^{3}+9 a b-27 c}{2 \sqrt{\left(a^{2}-3 b\right)^{3}}} \\
a=K_{\mathrm{d}, \mathrm{A}}+K_{\mathrm{d}, \mathrm{B}}+[\mathrm{A}]_{0}+[\mathrm{B}]_{0}-[\mathrm{P}]_{0} \\
b=K_{\mathrm{d}, \mathrm{B}}\left([\mathrm{A}]_{0}-[\mathrm{P}]_{0}\right)+K_{\mathrm{d}, \mathrm{A}}\left([\mathrm{B}]_{0}-[\mathrm{P}]_{0}\right)+K_{\mathrm{d}, \mathrm{A}} K_{\mathrm{d}, \mathrm{B}} \\
c=-K_{\mathrm{d}, \mathrm{A}} K_{\mathrm{d}, \mathrm{B}}[\mathrm{P}]_{0}
\end{gathered}
$$

and $[\mathrm{A}]_{0}=[\mathrm{A}]+[\mathrm{PA}],[\mathrm{B}]_{0}=[\mathrm{B}]+[\mathrm{PB}]$, and $[\mathrm{P}]_{0}=[\mathrm{P}]$ $+[\mathrm{PA}]+[\mathrm{PB}]$.

These solutions can be used to calculate the expected occupancy by pseudoazurin and cytochrome $c 550$ of a single site on cytochrome $c$ peroxidase if the $K_{\mathrm{d}}$ values are known. These equations were used in the analysis of binding in isothermal calorimetry, analytical ultracentrifugation, and ${ }^{1} \mathrm{H}$ NMR experiments.

Molecular Docking Simulation. Docking was performed as described in ref 10 using the algorithm BiGGER developed by Palma et al. (17). The target protein was the monomer of the cytochrome $c$ peroxidase. The coordinates for the mixed valence enzyme were kindly made available prior to publication by V. Fulop and A. Echalier. The coordinates for pseudoazurin (ADW.pdb) (18) were obtained from the National Center for Biotechnology information (http://www.ncbi.nlm.nih.gov/). The BiGGER algorithm provides a complete and systematic search of the rotational space of one protein relative to the other, generating a large number of candidate docking geometries based solely on the complementarity of the molecular surfaces. The 1000 best solutions thus generated were finally evaluated and ranked according to a combination of additional interaction criteria that include electrostatic energy of interaction, relative solvation energy, and the relative propensity of side chains to interact. For each solution, this combination process produces a "global score". In this particular case, we also applied a filter to the results based on the contacts determined by analysis of the chemical shift perturbation in heteronuclear

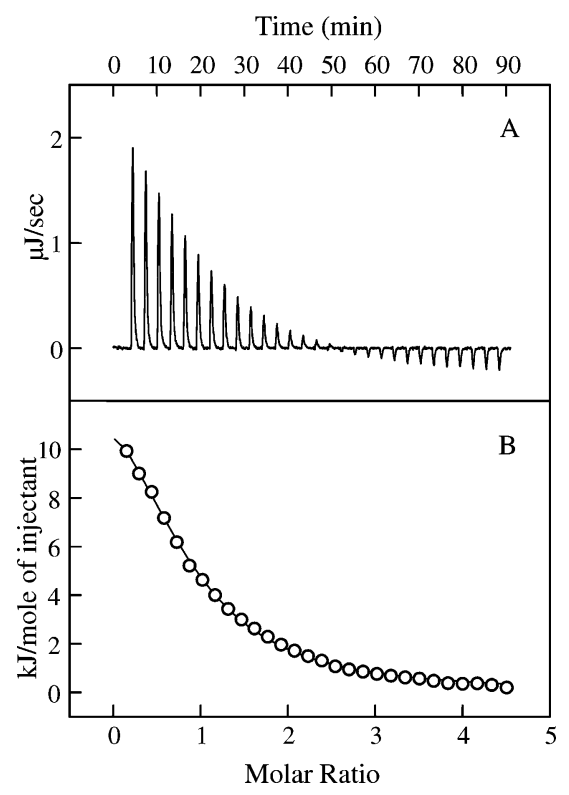

FIGURE 1: Isothermal titration calorimetry of the binding of pseudoazurin to Paracoccus cytochrome $c$ peroxidase. Paracoccus pseudoazurin and Paracoccus cytochrome $c$ peroxidase were equilibrated in $10 \mathrm{mM}$ cacodylate, $\mathrm{pH} 6.0,10 \mathrm{mM} \mathrm{NaCl}, 2 \mathrm{mM}$ $\mathrm{CaCl}_{2}$ by passage down a Sephadex $\mathrm{G} 25$ molecular exclusion column. The microcalorimetry chamber contained degassed cytochrome $c$ peroxidase $(35.9 \mu \mathrm{M})$ at $25^{\circ} \mathrm{C}$, and the syringe contained degassed pseudoazurin $(693 \mu \mathrm{M})$. A dilution titration was performed in which pseudoazurin was titrated into buffer alone (not shown). However, subtraction of that dilution titration from the experimental data did not prove to be completely satisfactory in allowing a subsequent single-set-of-sites fit. Instead an estimate was made of the small exothermic heat change at the end of the titration, and a fixed value was added to the experimental data. This allows the fit shown in panel B and with the parameters shown in Table 1.

${ }^{1} \mathrm{H}-{ }^{15} \mathrm{~N}$ NMR spectroscopy (1). This procedure is described in the Results section.

\section{RESULTS}

Formation of a Binary Complex of Pseudoazurin with Cytochrome c Peroxidase. (i) Isothermal Titration Calorimetry. The endothermic association of pseudoazurin and cytochrome $c$ peroxidase in cacodylate buffer at $\mathrm{pH} 6$ and an ionic strength of $0.026 \mathrm{M}$ is shown in Figure 1A. There is a small exothermic effect toward the end of the titration. This could represent a second weak exothermic binding process, and it could be fitted as such (although rather poorly) within a two sites model. However, dilution of pseudoazurin into buffer alone produces a similar steady exothermic effect (results not shown). This may be due to the monomerization of the protein that is partially dimeric at the concentration in the syringe. Although the titration data for pseudoazurin and cytochrome $c$ peroxidase can be fitted using a single set of sites model after subtraction of this dilution effect, a more satisfactory fit is achieved by addition of a constant value to the $y$ axis, and this has been done in Figure 1B. The thermodynamic parameters for this titration and for titrations conducted at the same ionic strength in Mes buffer, $\mathrm{pH}$ 6.0, and at an ionic strength of $0.046 \mathrm{M}$ in cacodylate buffer, pH 6.0, are shown in Table 1. Included in that table are results for the binding of horse cytochrome $c$ and cytochrome c550 to the Paracoccus cytochrome $c$ peroxidase (9).

Like cytochrome $c 550$, pseudoazurin binds at a single site, but the binding is weaker than is the case for cytochrome 
Table 1: Thermodynamic Parameters for the Binding of Redox Donors to Paracoccus Cytochrome $c$ Peroxidase at $25^{\circ} \mathrm{C}^{a}$

\begin{tabular}{|c|c|c|c|c|c|c|}
\hline buffer & $I(\mathrm{M})$ & $N$ & $\begin{array}{c}K_{\mathrm{a}}\left(\times 10^{5}\right) \\
\left(\mathrm{M}^{-1}\right)\end{array}$ & $\begin{array}{c}K_{\mathrm{d}} \\
(\mu \mathrm{M})\end{array}$ & $\begin{array}{c}\Delta H^{\circ} \\
\left(\mathrm{kJ} \mathrm{mol}^{-1}\right)\end{array}$ & $\begin{array}{c}\Delta S^{\circ} \\
\left(\mathrm{J} \mathrm{K}^{-1}\right. \\
\left.\mathrm{mol}^{-1}\right) \\
\end{array}$ \\
\hline \multicolumn{7}{|c|}{ Pseudoazurin } \\
\hline \multirow{3}{*}{$\begin{array}{l}\text { Mes, pH } 6 \\
\text { cacodylate, } \\
\text { pH } 6\end{array}$} & 0.026 & $0.86 \pm 0.02$ & $0.49 \pm 0.02$ & 20.3 & $17.1 \pm 0.5$ & 147 \\
\hline & 0.026 & $0.86 \pm 0.02$ & $0.61 \pm 0.02$ & 16.4 & $16.1 \pm 0.4$ & 146 \\
\hline & 0.046 & $0.96 \pm 0.03$ & $0.36 \pm 0.02$ & 27.5 & $11.7 \pm 0.5$ & 127 \\
\hline \multicolumn{7}{|c|}{ Cytochrome $c 550$ (from ref 9 ) } \\
\hline \multirow{2}{*}{$\begin{array}{c}\text { cacodylate, } \\
\text { pH } 6\end{array}$} & 0.026 & 1.04 & 2.7 & 3.7 & 10.4 & 139 \\
\hline & 0.046 & 1.09 & 2.3 & 4.3 & 9.6 & 135 \\
\hline \multicolumn{7}{|c|}{ Horse Cytochrome $c$ (from ref 9 ) } \\
\hline \multirow{2}{*}{$\begin{array}{c}\text { cacodylate, } \\
\text { pH } 6\end{array}$} & 0.026 & $(1.59)^{b}$ & 1.9 & 5.4 & 21.2 & 172 \\
\hline & 0.046 & $(1.33)^{b}$ & 0.64 & 15.7 & 19.5 & 157 \\
\hline
\end{tabular}

${ }^{a}$ The binding of redox donors to Paracoccus cytochrome $c$ peroxidase was studied in $10 \mathrm{mM}$ Mes, $10 \mathrm{mM} \mathrm{NaCl}, 2 \mathrm{mM} \mathrm{CaCl}_{2}$, pH 6.0 $(I=0.026 \mathrm{M}) ; 10 \mathrm{mM}$ cacodylate, $10 \mathrm{mM} \mathrm{NaCl}, 2 \mathrm{mM} \mathrm{CaCl}_{2}$, pH 6.0 $(I=0.026 \mathrm{M})$; and $10 \mathrm{mM}$ cacodylate, $30 \mathrm{mM} \mathrm{NaCl}, 2 \mathrm{mM} \mathrm{CaCl}{ }_{2}$, pH $6.0(I=0.046 \mathrm{M}) .{ }^{b}$ Horse cytochrome $c$ binds at two sites, and these values are the molar ratios derived from a single set of sites analysis (see ref 9).

c550. For both proteins, the reaction is strongly endothermic, and this is offset by a large favorable entropy change. An increase in the ionic strength from 0.026 to $0.046 \mathrm{M}$ weakens the binding of pseudoazurin by a factor of 1.7 , and this is associated with a diminished entropic driving force, although the enthalpy change actually becomes somewhat less unfavorable. The observed heat changes were almost independent of buffer, indicating that binding was probably not associated with loss of protons (which would be taken up by the buffer and contribute to the observed heat change). A release of 0.07 proton could be calculated as described in ref 9 .

(ii) Analytical Ultracentrifugation. Under the conditions of centrifugation, the cytochrome $c$ peroxidase is dimeric (9) and has a sedimentation coefficient of $4.8 \mathrm{~S}$ (Figure 2A). As the molar proportion of pseudoazurin was increased from 0.5 to 4 , the sedimentation coefficient of the leading boundary increased as shown in Figure 2A. In our analysis of the binding of cytochrome $c 550$ to the cytochrome $c$ peroxidase (9), we measured bound and free cytochrome by the absorbance values of the leading and trailing sedimentation boundaries, but this is not possible with pseudoazurin because of the very low extinction coefficient of the chromophore. As an alternative, we have used the shift in sedimentation coefficient as a measure of bound protein. The sedimentation coefficient is related to the relative molecular mass, $M_{\mathrm{r}}$, and the translational diffusion coefficient by the Svedberg equation,

$$
M_{\mathrm{r}}=s R T /(D(1-v \rho))
$$

We tried to evaluate $s / D$ values for the different experiments, but the estimates of $D$ based on the spreading of the boundary are unreliable due to the presence of more than one species in equilibrium. Instead we have used the power law relation between sedimentation coefficient and $M_{\mathrm{r}}$ (see, for example, ref 19),

$$
s_{\text {complex }} / s_{\text {enzyme }} \approx\left(M_{\mathrm{r}, \text { complex }} / M_{\mathrm{r}, \text { enzyme }}\right)^{x}
$$
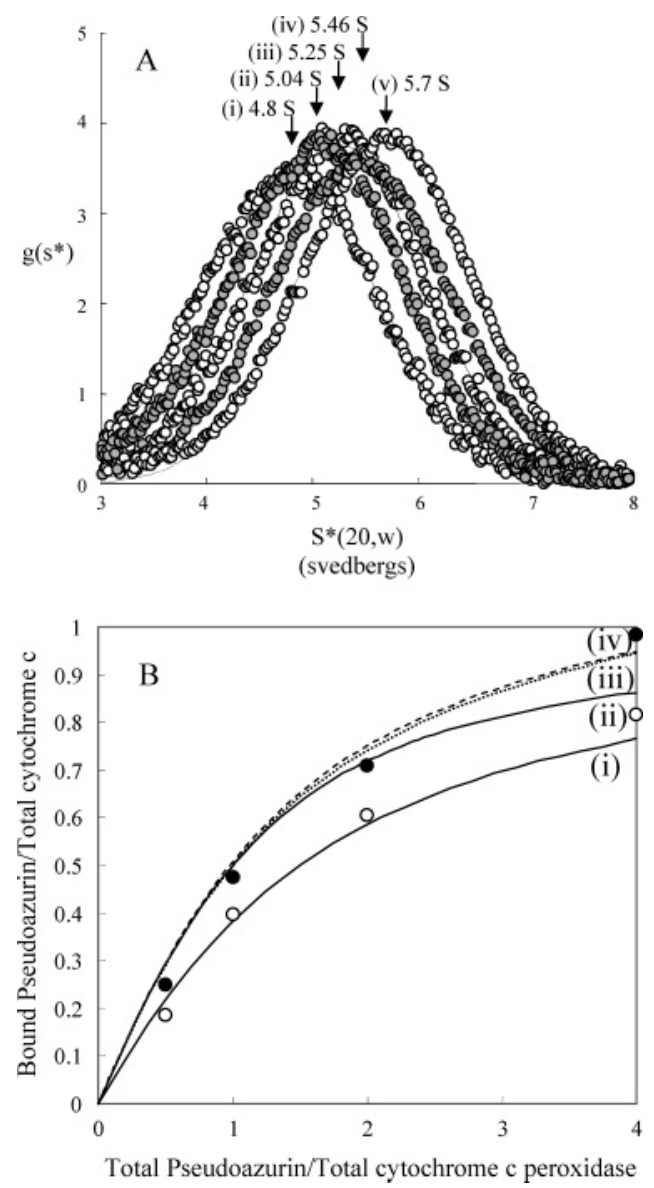

FIGURE 2: The effect of pseudoazurin binding on the sedimentation coefficient of cytochrome $c$ peroxidase. In panel A, sedimentation velocity experiments were performed in $10 \mathrm{mM} \mathrm{Mes}, 10 \mathrm{mM} \mathrm{NaCl}$, and $2 \mathrm{mM} \mathrm{CaCl}_{2}$ at $\mathrm{pH} 6.0,25^{\circ} \mathrm{C}$, and $45000 \mathrm{rpm}$. Paired scans within a set of 10 sequential scans were used to produce a distribution of sedimentation coefficients using the DCDT+ method of Philo (15): (i) white circles, $40 \mu \mathrm{M}$ cytochrome $c$ peroxidase (4.8 S); (ii) gray circles, $40 \mu \mathrm{M}$ cytochrome $c$ peroxidase and 20 $\mu \mathrm{M}$ pseudoazurin $(5.04 \mathrm{~S})$; (iii) white circles, $40 \mu \mathrm{M}$ cytochrome $c$ peroxidase and $40 \mu \mathrm{M}$ pseudoazurin $(5.25 \mathrm{~S}$ ); (iv) gray circles, $40 \mu \mathrm{M}$ cytochrome $c$ peroxidase and $80 \mu \mathrm{M}$ pseudoazurin $(5.46$ $\mathrm{S}$ ); (v) white circles, $40 \mu \mathrm{M}$ cytochrome $c$ peroxidase and $160 \mu \mathrm{M}$ pseudoazurin $(5.7 \mathrm{~S})$. The theoretical fits to the data (solid lines) gave the sedimentation coefficients shown. Panel B shows saturation curves for the binding of pseudoazurin to cytochrome $c$ peroxidase. The results are based on the analysis of sedimentation velocity profiles (part A) for experiments run in $10 \mathrm{mM}$ Mes buffer, 10 $\mathrm{mM} \mathrm{NaCl}, 2 \mathrm{mM} \mathrm{CaCl} 2, \mathrm{pH} 6.0,25^{\circ} \mathrm{C}, 45000 \mathrm{rpm}$. Paired scans within a set of 10 sequential scans were used to produce a distribution of sedimentation coefficients using the DCDT+ method of Philo (15): (O) binding of pseudoazurin to $20 \mu \mathrm{M}$ cyochrome $c$ peroxidase; (O) binding of pseudoazurin to $40 \mu \mathrm{M}$ cytochrome $c$ peroxidase. These values were calculated from the experimentally determined sedimentation coefficients using the relationship (see Results section) $s_{\text {complex }} / s_{\text {enzyme }}=\left(M_{\mathrm{r}, \text { complex }} / M_{\mathrm{r} \text {,enzyme }}\right)^{0.57}$. The derived values of $M_{\mathrm{r} \text {,complex }}$ were used to obtain the added $M_{\mathrm{r}}$ due to the bound pseudoazurin, and this was expressed as a proportion of 26810 , which is the added $M_{\mathrm{r}}$ that would correspond to a pseudoazurin binding to each monomer of the dimeric protein. The solid line $\mathrm{i}$ associated with results for $20 \mu \mathrm{M}$ cytochrome $c$ peroxidase $(O)$ is a theoretical line for a $K_{\mathrm{d}}$ of $20.3 \mu \mathrm{M}$. The solid line ii associated with results for $40 \mu \mathrm{M}$ cytochrome $c$ peroxidase (•) is a theoretical line for a $K_{\mathrm{d}}$ of $20.3 \mu \mathrm{M}$. The dotted line iii is a theoretical line for the binding of pseudoazurin to one site (40 $\mu \mathrm{M})$ with a $K_{\mathrm{d}}$ of $20.3 \mu \mathrm{M}$ and a second pseudoazurin binding to a pseudoazurin already bound to the cytochrome $c$ peroxidase with a $K_{\mathrm{d}}$ of $800 \mu \mathrm{M}$. The dashed line iv is a theoretical line for the binding of pseudoazurin to two independent sites (each $40 \mu \mathrm{M}$ ) with $K_{\mathrm{d}}$ values of 20.3 and $1200 \mu \mathrm{M}$. 
to provide an estimate of the additional $M_{\mathrm{r}}$ associated with a shift in the $s$ value on complex formation. The limits of the conformation-dependent parameter $x$ are $\sim 0.67$ for spherically shaped molecules (and sphere-like complexes) and $\sim 0.15$ for rod shapes. We have varied the value of $x$ to obtain a fit between the experimental results and a binding curve defined by a $K_{\mathrm{d}}$ of $20.3 \mu \mathrm{M}$ (see Table 1 ). A value of 0.57 produces the fits shown in Figure $2 \mathrm{~B}$ for the two concentrations of cytochrome $c$ peroxidase. This value of 0.57 is consistent with the fact that the dimeric structure of the cytochrome $c$ peroxidase itself is somewhat elongated and the binding proteins add to the elongated axis. However, although the experimental results expressed in this way show reasonable agreement with the theoretical curves up to a molar proportion of 2 pseudoazurin to 1 peroxidase, they deviate at the highest molar proportion, and this is more pronounced with the experiment containing the higher concentration of cytochrome $c$ peroxidase (closed circles).

There are two possible explanations for this finding which we cannot distinguish on the basis of this evidence alone. One is that there is a second weak binding site for the pseudoazurin on the peroxidase. In Figure 2B, curve iv (dashed line) is a theoretical line for two independent sites, the second with a $K_{\mathrm{d}}$ value of $1200 \mu \mathrm{M}$. The second possibility is that free pseudoazurin can bind weakly to the already bound pseudoazurin to form a bound dimer. This is more complex to analyze because the target (i.e., the peroxidase with bound pseudoazurin monomer) will be increasing in concentration as the total pseudoazurin is increased and the weak dimerization equilibrium will mean that, in the initial stages, the pseudoazurin will bind as a monomer to vacant peroxidase sites with very little tendency to dimerize either in solution or on the peroxidase itself. A theoretical simulation of these effects is shown on Figure 2B, curve iii (dotted line), with a $K_{\mathrm{D}}$ for dimerization of 800 $\mu \mathrm{M}$ and a $K_{\mathrm{D}}$ for binding of pseudoazurin to cytochrome $c$ peroxidase of $20.3 \mu \mathrm{M}$.

Although the theoretical curves iii and iv of Figure 2B are very similar and cannot be used to choose one model over another, we already know that pseudoazurin does dimerize. Williams et al. (18) quote a figure for $K_{\mathrm{d}}$ of 606 $\mu \mathrm{M}$ for experiments run in $20 \mathrm{mM}$ phosphate, $\mathrm{pH}$ 7.0. We therefore consider it likely that the sedimentation behavior can be explained by a dimerization effect at high pseudoazurin concentrations. Interestingly, this implies that the interface involved in dimerization is available in the binary complex of the pseudoazurin with the cytochrome $c$ peroxidase. We will return to that point in the section on molecular docking.

(iii) ${ }^{l}$ H NMR Spectroscopy. We have conducted ${ }^{1} \mathrm{H}$ NMR spectroscopy at $\mathrm{pH} 7.5$ rather than at $\mathrm{pH} 6$ (the conditions of previous work (8)) because the position of the heme methyl resonances of cytochrome $c$ peroxidase are strongly pH-dependent (Prazeres, S. (1995) Unpublished observations, $\mathrm{PhD}$ thesis, Universidade Nova de Lisboa). The $\mathrm{p} K$ for this transition is near $\mathrm{pH} 6$, and this means that the titration of one protein solution against another is susceptible to small differences in solution $\mathrm{pH}$. The iron of the electrontransferring heme in the oxidized form of the enzyme is in a rapid low spin-high spin equilibrium (at room temperature), and its methyl resonances are strongly downfield shifted to appear between 63 and 53 ppm (Figure 3A,B).
The binding of pseudoazurin induces changes in the chemical shift of these resonances that is consistent with a binding close to the electron-transferring heme (Figure 3A, spectrum ii). In contrast, the chemical shifts of the methyl resonances of the peroxidatic heme are unaffected by the binding of the pseudoazurin (data not shown). The chemical shift variation shows that the complex is in fast exchange on the NMR time scale. Binding of pseudoazurin affects mostly the M1/M2 and M3 heme methyl resonances of the $\mathrm{E}$ heme (compare spectra $\mathrm{i}$ and ii in Figure 3A), and the analysis of the induced chemical shift variation of the M3 heme methyl resonance gave a stoichiometry of $1: 1$ for the formation of the complex (Figure 3C) with a $K_{\mathrm{d}}$ of $4.4 \mu \mathrm{M}$. The discrepancy with the value of $20.3 \mu \mathrm{M}$ obtained by microcalorimetry may be due to the lower ionic strength, the higher $\mathrm{pH}$, or both of the NMR titration.

In contrast, the binding of cytochrome c550 to the peroxidase mainly affects heme methyl 4 (compare $\mathrm{i}$ and ii in Figure 3B), but the stoichiometry of the complex is also $1: 1$ (data not shown), as had been previously observed at pH 6.0 (9).

(iv) Docking of Pseudoazurin to Cytochrome c Peroxidase. Pettigrew et al. (9) found that the "soft" docking mode of BiGGER was preferred for the docking of cytochrome $c 550$ to the cytochrome $c$ peroxidase, and we have found the same for pseudoazurin. The soft-docking results are shown in Figure 4A and show that a decisive pattern is not obtained; high-ranking solutions occur at several points on the molecular surface including the edge of the electron-transferring heme. However, in this case, we can apply a filter to the docking data based on the residues in pseudoazurin that experience shifts in the amide ${ }^{1} \mathrm{H}$ or ${ }^{15} \mathrm{~N}$ resonances in chemical shift perturbation studies with cytochrome $c$ peroxidase (1). It is clear from the chemical shift data that some residues in pseudoazurin are affected directly by contact with the peroxidase while others are the result of secondary "knock-on" effects (1). We have used what we regard as primary contacts that are situated on a single surface of the pseudoazurin, which contains the proposed electron-transfer site at histidine 81 . There are 18 such contacts. The collection of docking solutions are evaluated for how many of this contact list come within $6 \AA$ of the peroxidase surface. The results of the application of the contact filter are shown in Figure 4B. Again a number of clusters appear at different locations on the molecular surface. As a final step, the list of solutions with highest contacts ( 15 or above, 82 solutions) is compared with a list of the same size based on global score. The solutions common to the two lists (the intercept solutions) are then displayed (Figure 4C). We conclude that, on the basis of a combination of global score and contacts score (Table 2), a group of solutions can be identified that lie close to the electron-transferring heme. This group is shown in Figure 5A, and the four members of the group have a $\mathrm{Cu}-\mathrm{Fe}$ distance of $13.8-14.6 \AA$ (Table 2).

Comparison of these docking solutions with the crystallographic dimer of pseudoazurin (Figure 5B) indicates that a second pseudoazurin monomer would be able to bind to the one already associated with the peroxidase. This is consistent with the results of ultracentrifugation, which indicated that the peroxidase can bind a pseudoazurin dimer at high pseudoazurin concentrations (Figure 2B). 

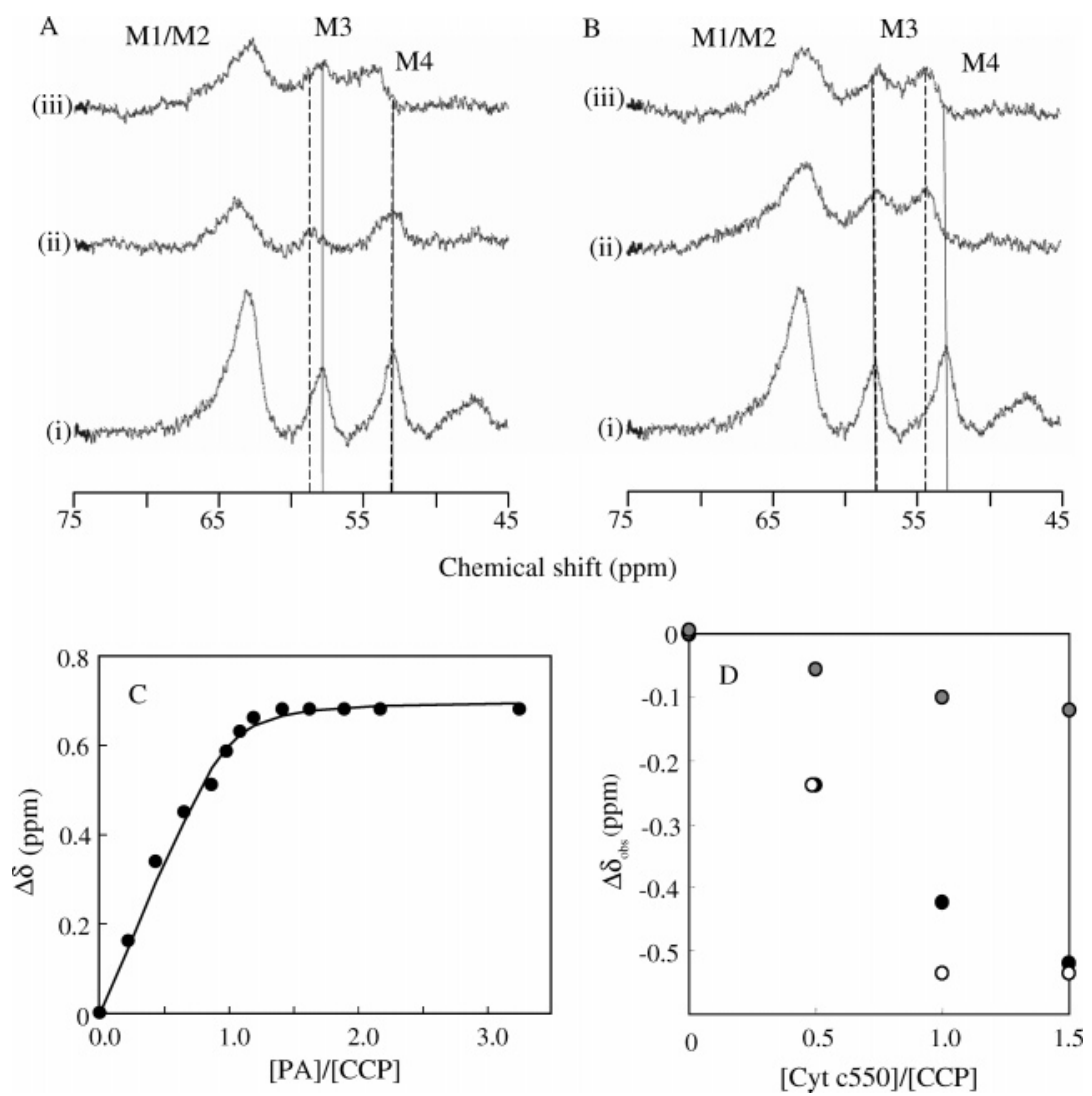

FIGURE 3: ${ }^{1} \mathrm{H}$ NMR titration of cytochrome $c$ peroxidase with its electron donors, pseudoazurin and cytochrome $c 550$. In panels A and B, the low-field spectral region (75-45 ppm) containing the peroxidase M1/M2, M3, and M4 heme methyl resonances is shown. The experiment was performed in a $500 \mathrm{MHz}$ spectrometer, and protein samples were in $10 \mathrm{mM}$ Hepes, $2 \mathrm{mM} \mathrm{CaCl} 2, \mathrm{pH} 7.5,10 \% \mathrm{D}_{2} \mathrm{O}$ : $(\mathrm{A}, \mathrm{i}) 188 \mu \mathrm{M}$ cytochrome $c$ peroxidase; (A, ii) $173 \mu \mathrm{M}$ peroxidase and $374 \mu \mathrm{M}$ pseudoazurin; (A, iii) $177 \mu \mathrm{M}$ peroxidase, $260 \mu \mathrm{M}$ pseudoazurin, and 175 $\mu \mathrm{M}$ cytochrome $c_{550}$; (B, i) $188 \mu \mathrm{M}$ cytochrome $c$ peroxidase; (B, ii) $169 \mu \mathrm{M}$ peroxidase and $252 \mu \mathrm{M}$ cytochrome $c_{550}$; (B, iii) $170 \mu \mathrm{M}$ peroxidase, $252 \mu \mathrm{M}$ cytochrome $c_{550}$, and $184 \mu \mathrm{M}$ pseudoazurin. Panel C shows the chemical shift variation of the electron-transferring heme methyl, M3, of cytochrome $c$ peroxidase with increasing molar ratios of pseudoazurin. The fitting curve was simulated for a single binding site with $K_{\mathrm{d}}=4.4 \mu \mathrm{M}$ and $\delta_{\max }=0.7 \mathrm{ppm}$. Panel D shows a simulation of NMR titrations of complexes in competition. Proteins were prepared in $10 \mathrm{mM}$ Hepes buffer, $\mathrm{pH} 7.5,2 \mathrm{mM} \mathrm{CaCl}_{2}, 10 \% \mathrm{D}_{2} \mathrm{O}$. To the binary complex of cytochrome $c$ peroxidase and pseudoazurin $(0.2 \mathrm{mM})$ was added cytochrome $c 550$ up to a 1.5 molar ratio. Experimental values for the shift in the resonance of heme methyl 3 are shown as open circles. Chemical shift variation determined as described in the Materials and Methods for competitive binding is shown as black circles, and that for simultaneous binding at separate sites is shown as gray circles.

The chemical shift perturbation map of ref 1 for the binding surface of pseudoazurin for cytochrome $c$ peroxidase is compared in Figure 6 with the surface concealed by cytochrome $c$ peroxidase in the highest ranked docked solution in which the pseudoazurin lies adjacent to the $\mathrm{E}$ heme (solution 2 of Table 2, blue in Figure 5). There is a fair but not exact correspondence between the two.

Can Pseudoazurin and Cytochrome c550 Form a Ternary Complex with Cytochrome c Peroxidase? (i) Isothermal Calorimetry. When cytochrome $c 550$ was added to a solution containing cytochrome $c$ peroxidase and pseudoazurin in the molar proportions 1:5.9 (closed circles, Figure 7A), an exothermic heat change was observed, which diminished as the titration proceeded. This contrasts with the clearly endothermic binding pattern obtained (Figure 7A, open circles) when cytochrome $c 550$ is added to the peroxidase alone.

When pseudoazurin was added to a solution containing cytochrome $c$ peroxidase and cytochrome $c 550$ in the proportions 1:3.7 (closed circles, Figure 7B), very little heat change was observed. This contrasts with the clearly endothermic binding pattern obtained (Figure 7B, open circles) when pseudoazurin is added to the peroxidase alone. These two results indicate that binding to independent sites is not taking place.

The approach of Wang (16) and Sigurskjold (20) was used to simulate heat changes that would be observed in a competitive displacement process assuming the $K_{\mathrm{d}}$ values and $\Delta H$ values of Table 1 . These simulations are shown as theoretical lines in Figure 7A,B for the addition of cytochrome $c 550$ to a solution of peroxidase and pseudoazurin and for the addition of pseudoazurin to a solution of peroxidase and cytochrome $c 550$, respectively. We have not attempted to correct the titration data for the dilution effect referred to in the section on isothermal microcalorimetry of the binary complex above, so in the following description, we are referring to trends rather than fits.

According to a competitive displacement model, the incoming redox protein will displace some of the existing redox protein and also occupy additional unfilled sites. The relative enthalpies of binding are such that a displacement of pseudoazurin by incoming cytochrome $c 550$ will be a net exothermic process as shown in the simulation (Figure 7A, solid line) and in the sample calculation in Table 3 for the point in Figure 7A indicated by the arrow. This net exothermic process, dominated by the pseudoazurin displace- 


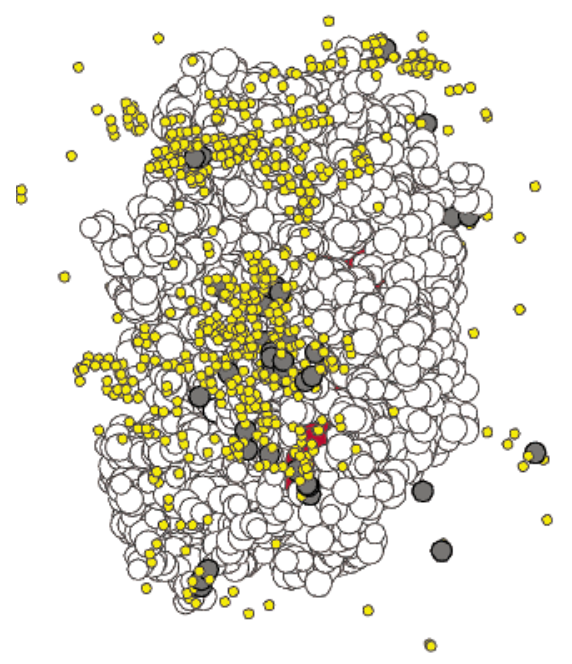

A

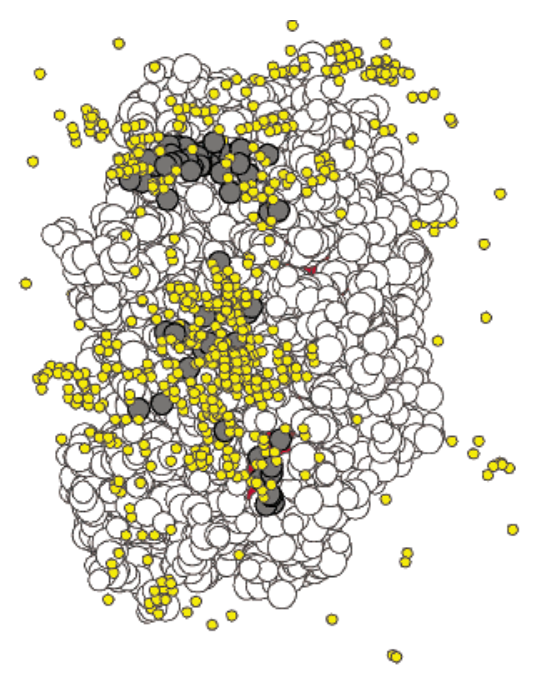

B

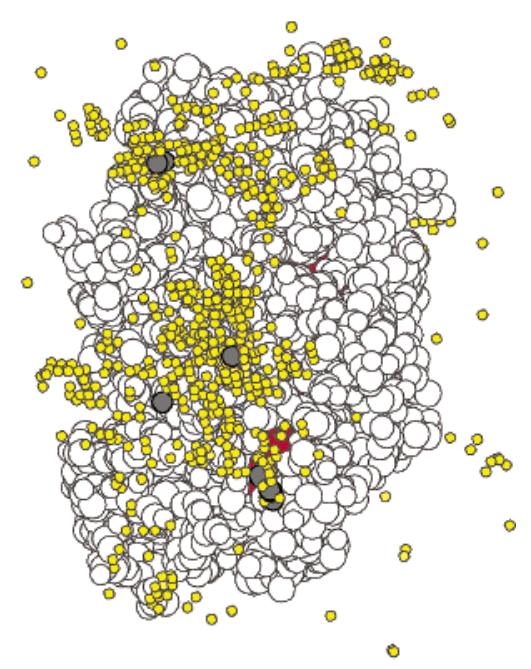

$\mathrm{C}$

FIGURE 4: Docking of pseudoazurin to cytochrome $c$ peroxidase of Paracoccus pantotrophus. The atoms of the side of the peroxidase monomer at which the E-heme is exposed are shown as gray circles with the $\mathrm{P}$ and $\mathrm{E}$ hemes in red and partially visible. The $\mathrm{E}$ heme is the more-exposed and is in the lower half of the peroxidase surface; the P heme is mostly buried, and small portions of it can be seen in the upper half of the peroxidase surface. The 1000 solutions filtered by BiGGER on the basis of surface complementarity are shown as small yellow circles, each representing the copper of the probe protein, pseudoazurin. Some lower-ranking solutions have been removed to see the position of the top-ranking solutions (larger gray circles) clearly. Also, not all solutions are visible in this view. Many are at the dimer interface of the peroxidase at the "back" of this view and can be ignored because the enzyme is known to function as a dimer. The 82 top solutions ranked on the basis of "global score" (see Materials and Methods) are shown in panel A as larger gray circles. Panel B shows ranking on a different basis. The amide resonances of 18 residues of the "front" surface of pseudoazurin were shown to be perturbed by binding to the cytochrome $c$ peroxidase (1). Solutions were ranked on the basis of how many of this set of 18 residues came within $6 \AA$ of the peroxidase surface. Eighty-two solutions showed 15 or more contacts according to this criterion and are shown as larger gray circles in B. The two groups of 82 solutions in panels A and B were compared, and those 14 common to the two groups were identified and are shown as larger gray circles in C. We call these the "intercept" solutions (Table 3).

ment, contains an endothermic contribution from cytochrome c550 binding to sites vacated by pseudoazurin and also cytochrome $c 550$ binding to additional vacant sites. However, the calculations of Table 3 show that increase in overall occupancy is very small, and therefore, the endothermic contribution of cytochrome $c 550$ binding to additional vacant sites is also small.

In contrast, the addition of pseudoazurin to a solution containing peroxidase and cytochrome $c 550$ shows a very small endothermic effect in the early stages (Figure 7B, solid line). This is the mirror of the effect seen in the reciprocal titration and again reflects the higher enthalpy of binding of the pseudoazurin. However, the net endothermic heat change is much smaller than the net exothermic heat change for the reciprocal titration of Figure 7A (closed circles) because the displacement of the cytochrome $c 550$ by the more weakly binding pseudoazurin is much more limited. Indeed, late in the titration, the heat change switches to a small exothermic effect, and this is due to the very small changes in site occupancy coupled with the fact that dilution of sites is becoming a significant effect.

We conclude that the microcalorimetry is consistent with competitive rather than additive binding.

(ii) Analytical Centrifugation. Under the conditions of centrifugation, the cytochrome $c$ peroxidase is dimeric and has a sedimentation coefficient of $4.78 \mathrm{~S}$ (Figure 8 ). In the presence of equimolar pseudoazurin (40 $\mu \mathrm{M}, M_{\mathrm{r}} 13405$ ), the leading boundary has a sedimentation coefficient of 5.24 $\mathrm{S}$ (Table 4). A site occupancy of 0.5 can be calculated for the pseudoazurin under these conditions using the $K_{\mathrm{d}}$ of 20.3 $\mu \mathrm{M}$ derived from microcalorimetry and assuming a single site. In the presence of cytochrome $c 550\left(M_{\mathrm{r}} 14815\right)$ in molar proportions of 2:1 cytochrome/peroxidase, the leading boundary had a sedimentation coefficient of $5.54 \mathrm{~S}$ (Table 4). A site occupancy of 0.94 can be calculated for the cytochrome c550 under these conditions using the $K_{\mathrm{d}}$ of $2.8 \mu \mathrm{M}$ derived from microcalorimetry (9) and assuming a single site (Table $4)$. In the presence of all three proteins in the proportions of 2:1:1 cytochrome $c 550 /$ pseudoazurin/cytochrome $c$ peroxidase, the leading boundary had a sedimentation coefficient of $5.65 \mathrm{~S}$, and the competitive binding equations of Wang (16) predict a pseudoazurin occupancy of 0.09 and a cytochrome $c 550$ occupancy of 0.86 , yielding a total occupancy of 0.95 (Table 4).

Using these figures, we can calculate the added $M_{\mathrm{r}}$ due to binding of the pseudoazurin and the cytochrome $c 550$ according to either the competitive binding scenario or an additive independent binding of the two proteins. Using the equation in the legend to Table 4 , we can use these added $M_{\mathrm{r}}$ values to predict a sedimentation coefficient for each model. The experimentally observed value of 5.65 is close to the theoretical figure of 5.56 for competitive binding and remote from the theoretical figure of 5.94 for additive binding. These theoretical values are indicated in Figure 8 as arrows. We conclude that competitive rather than additive binding has been demonstrated.

(iii) ${ }^{1} H$ NMR Spectroscopy. Key to the interpretation of Figure 3 is the observation that binding of pseudoazurin has very little effect on methyl resonance 4 , while binding of cytochrome $c 550$ has very little effect on methyl resonance 3 (compare Figure 3A, spectra i and ii, with Figure 3B, spectra $\mathrm{i}$ and ii). When cytochrome c550 is added to a solution already containing pseudoazurin and cytochrome $c$ peroxidase, the shift in the M4 resonance clearly indicates 
Table 2: Docking Solutions at the Intercept ${ }^{a}$ between Global Scoring and Contact Scoring

\begin{tabular}{ccccl}
\hline $\begin{array}{c}\text { solution } \\
\text { no. }\end{array}$ & $\begin{array}{c}\text { contacts } \\
\text { (out of 18) }\end{array}$ & $\begin{array}{c}\text { global } \\
\text { score }\end{array}$ & $\begin{array}{c}\mathrm{Cu}-\mathrm{Fe} \\
\text { distance }^{b}(\AA)\end{array}$ & \multicolumn{1}{c}{ location $^{c}$} \\
\hline$(1$ & 17 & -79.4 & 19.4 & interface) \\
$\mathbf{2}$ & $\mathbf{1 6}$ & $\mathbf{- 8 4 . 0}$ & $\mathbf{1 4 . 6}$ & front, $\mathbf{E}$ heme \\
$(3$ & 16 & -81.6 & 33.7 & interface) \\
$\mathbf{4}$ & $\mathbf{1 6}$ & $-\mathbf{8 0 . 7}$ & $\mathbf{1 4 . 5}$ & front, $\mathbf{E}$ heme \\
$(5$ & 16 & -79.8 & 21.1 & interface) \\
$(6$ & 16 & -79.7 & 20.8 & interface) \\
7 & 16 & -76.2 & 37.7 & front \\
8 & 16 & -75.5 & 37.9 & front \\
$(9$ & 16 & -75.4 & 21.0 & interface) \\
$\mathbf{1 0}$ & $\mathbf{1 5}$ & $-\mathbf{8 0 . 7}$ & $\mathbf{1 3 . 8}$ & front, $\mathbf{E}$ heme \\
$(11$ & 15 & -78.6 & 31.9 & interface) \\
12 & 15 & -77.6 & 18.2 & front \\
13 & 15 & -76.7 & 18.3 & front \\
$\mathbf{1 4}$ & $\mathbf{1 5}$ & $\mathbf{- 7 6 . 5}$ & $\mathbf{1 4 . 5}$ & front, $\mathbf{E}$ heme \\
\hline
\end{tabular}

${ }^{a}$ The amide resonances of 18 residues in pseudoazurin (N9, M16, D37, K38, S39, E43, A44, K46, K59, I60, N61, K77, T79, H81, G83, M84, K109, and K110) situated on the face of the molecule surrounding the electron-transfer site at His 81 were found to be shifted in the presence of the cytochrome $c$ peroxidase (1). These are a subset of the 45 residues that experienced some change in their chemical shift on binding to the peroxidase, but we have argued (1) that a number of these are the result of secondary effects due to subtle structural changes at the interface. The 1000 docking solutions were evaluated for how many of these contact residues came within $6 \AA$ of the cytochrome $c$ peroxidase surface. There were 82 solutions that satisfied 15 or more contacts ( 1 had 18 contacts, 9 had 17 contacts, 32 had 16 contacts, and 40 had 15 contacts). As a separate procedure, the top 82 solutions sorted on the basis of the "global score" of the BiGGER algorithm were also selected. Comparison of the "contacts list" and the "global score list" revealed the presence of 14 "intercept" solutions, which are shown here. They are ranked in order of number of contacts and then within each rank according to global score. ${ }^{b}$ This is the distance between the copper center of pseudoazurin and the iron of the electron-transferring heme of the peroxidase. ${ }^{c}$ Three general locations are given: (i) Docking was done with the monomer of the peroxidase for reasons explained in ref 10. Interface solutions occur at the surface between the two monomers and are therefore impossible in the active dimeric enzyme. Interface solutions are shown in parentheses. (ii) "Front" solutions occur on the surface shown in Figure 4. All the intercept front solutions are shown in Figure 4C (eight solutions including four at the E heme). (iii) "Front, E-heme" solutions are front solutions that are positioned near the electron-transferring heme. They are shown in bold. They are represented as a group in Figure 5.

binding of the cytochrome $c 550$, and the shift in the M3 resonance clearly indicates the dissociation of pseudoazurin (compare Figure 3A, spectra ii and iii). This indicates qualitatively that competitive displacement has taken place, and this was further analyzed mathematically (16). The theoretical plots for an additive binding effect of the two proteins and a displacement effect are compared with the experimental results for the chemical shift variation in heme methyl 3 in Figure 3D. It is clear that the experimental results are compatible with a competitive displacement. (We should note here that the $K_{\mathrm{d}}$ values used for the analysis of competitive binding are those obtained by microcalorimetry at $\mathrm{pH} 6.0$ (Table 1). We have attempted to perform microcalorimetry in the $10 \mathrm{mM}$ Hepes, $\mathrm{pH} 7.5,2 \mathrm{mM} \mathrm{CaCl}_{2}$ buffer used for the ${ }^{1} \mathrm{H}$ NMR spectroscopy, but there are problems in the analysis of the binding of both pseudoazurin and cytochrome $c 550$. In the former case, there is a slow exothermic effect, probably due to monomerization as a result of the dilution of the pseudoazurin, which makes adjustment of the baselines of the heat change profile difficult. In the latter case, there is only a small net endothermic response,
Table 3: Illustration of the Calculation of Theoretical Heat Changes Using a Competitive Binding Model

\begin{tabular}{|c|c|c|c|c|}
\hline \multicolumn{5}{|c|}{$\begin{array}{l}\text { Addition of Cytochrome c550 to a Mixture of } \\
\text { Peroxidase and Pseudoazurin (Figure 7A) }\end{array}$} \\
\hline \multicolumn{2}{|c|}{$\operatorname{addition}^{a}$} & $\begin{array}{l}\text { occupancy }^{b} \\
(\mathrm{c} 550)\end{array}$ & $\begin{array}{l}\% \text { occupancy } \\
\text { (PA) }\end{array}$ & $\begin{array}{c}\text { total } \\
\text { occupancy }\end{array}$ \\
\hline \multicolumn{2}{|c|}{3} & 13.5 & 75.55 & 89.05 \\
\hline \multicolumn{2}{|c|}{4} & 19.1 & 70.7 & 89.80 \\
\hline & $\begin{array}{c}{\left[\Delta_{\text {occupancy }}\right]^{c}} \\
\quad(\mu \mathrm{M})\end{array}$ & $\begin{array}{c}\Delta_{\text {occupancy }}{ }^{d} \\
(\mathrm{nmol})\end{array}$ & $\begin{array}{l}\text { heat change/ } \\
\text { injection }(\mathrm{J})\end{array}$ & \\
\hline c550 & +1.20 & +1.68 & $+1.75 \times 10^{-5}$ & $\begin{array}{l}\text { net heat change } \\
\text { at addition } 4= \\
-0.93 \times 10^{-5} \\
\text { J/injection }\end{array}$ \\
\hline PA & -1.19 & -1.67 & $-2.68 \times 10^{-5}$ & $\begin{array}{c}\text { heat change } / \text { mole } \\
\text { of injectant }= \\
-1.82 \mathrm{~kJ} / \mathrm{mol}\end{array}$ \\
\hline
\end{tabular}

${ }^{a}$ The additions refer to the stages during the titration shown in Figure 7A (closed circles). ${ }^{b}$ The occupancy of the site for a particular binding protein is the concentration of the bound protein calculated from the competitive binding equations of Wang (16) (Materials and Methods). By dividing this bound protein concentration by the peroxidase concentration, the \% occupancy can be calculated, and then the total occupancy is the sum of the occupancies for the two individual proteins. These calculations must take into account the dilution that is occurring in the chamber as the titration progresses. This is done using the equations (19) $C_{\mathrm{x}}=C_{\mathrm{o}}\left(1-\mathrm{e}^{-V_{\mathrm{x}} / V_{\mathrm{o}}}\right)$ and $P_{\mathrm{x}}=P_{\mathrm{o}} \mathrm{e}^{-V_{\mathrm{x}} / V_{\mathrm{o}}}$, where $C_{\mathrm{x}}$ and $P_{\mathrm{x}}$ are the concentrations of the titrant and the peroxidase at a certain stage in the titration, $C_{\mathrm{o}}$ and $P_{\mathrm{o}}$ are the starting concentrations of the titrant and the peroxidase, and $V_{\mathrm{x}}$ and $V_{\mathrm{o}}$ are the volume of titrant added and the volume of the chamber $(1.4 \mathrm{~mL})$, respectively. ${ }^{c}\left[\Delta_{\text {occupancy }}\right]$ is the change in occupying concentration of one binding protein after one addition. ${ }^{d} \Delta_{\text {occupancy }}$ is the change in the occupying amount of one binding protein after one addition. This can be used to calculate the expected heat change due to that injection and due to each binding protein using the enthalpy changes of Table 1 . The two heat changes for the two binding proteins are then summed to give the overall heat change, which can be expressed per mole of injectant and plotted in Figure 7 as theoretical curves. The result of this particular calculation is indicated by the arrow in Figure 7.

probably because of substantial proton release into the Hepes buffer, which has a high enthalpy of ionization.)

\section{DISCUSSION}

Pseudoazurin Has a Single Binding Site on Cytochrome c Peroxidase. The isothermal microcalorimetry data (Figure 1) can be fitted well to a single site after addition of a constant correction to the heat changes. The need for this correction is undoubtedly linked to the fact that a titration of pseudoazurin into buffer alone yields a steady small exothermic heat change. This is consistent with the presence of a monomer-dimer equilibrium in the syringe that is pulled toward monomerization in the chamber. If a two-sets-ofsites model is applied to the uncorrected data, a fit can be obtained (albeit a poor one) for a high-affinity endothermic binding along with a low-affinity exothermic binding. Although the latter could, in principle, represent a second weak binding site (as has been seen, for example, in yeast cytochrome $c$ peroxidase (21)), the known monomer-dimer equilibrium for the pseudoazurin affords a sufficient explanation. We are faced with a similar situation in the analysis of the sedimentation velocity ultracentrifugation data. It is clear that, at higher concentrations of pseudoazurin (Figure 2), the 

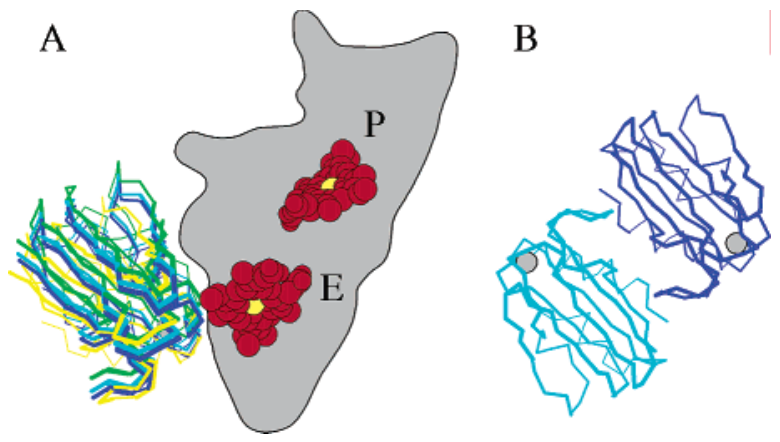

FIGURE 5: A cluster of solutions at the electron-transferring heme of cytochrome $c$ peroxidase. In panel A, the four intercept solutions that bind near to the electron-transferring heme (Figure 4C, Table 3 ) are shown superimposed (2, blue; 4 , turquoise; 10 , green; 14 , yellow). The orientation is $90^{\circ}$ relative to that shown in Figure 4 , and the right side surface of the peroxidase shown here forms the dimer interface with a second monomer. The polypeptide chains are represented by linked $\alpha$-carbon atoms, and the copper as a small gray circle. The outline of the cytochrome $c$ peroxidase monomer is shown in gray with the electron-transferring heme $(\mathrm{E})$ and the peroxidatic heme $(\mathrm{P})$ in red and the irons as yellow circles. In panel $\mathrm{B}$, the two monomers of the pseudoazurin dimer (18) are represented by linked $\alpha$-carbon atoms and the copper as a gray circle. The orientation is set to resemble the orientation of the bound pseudoazurin monomers in panel $\mathrm{A}$ and to show that a second pseudoazurin monomer is capable of binding to a pseudoazurin already bound to the peroxidase.

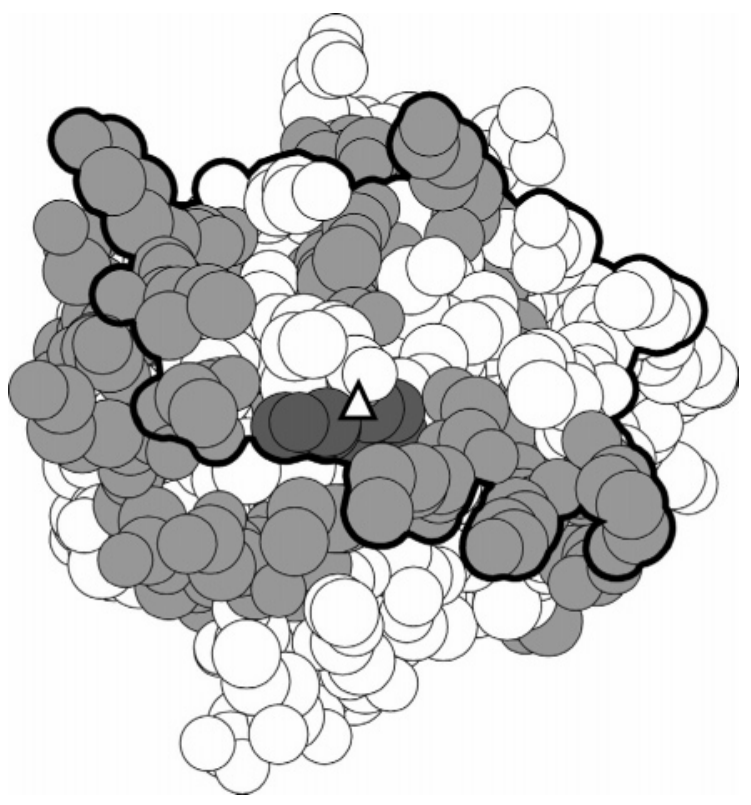

FIGURE 6: The binding surface on pseudoazurin-comparison of the chemical shift perturbation map (ref 1) with the interface of the docked complex. The front view of pseudoazurin (rendered by the molecular graphics program 'MacImdad') is defined by the presence of His81 (dark gray circles) and is centered on the dipole, which is perpendicular to the plane of the page (triangle). The light gray circles are those residues that experience chemical shift perturbation of greater than 0.05 for ${ }^{15} \mathrm{~N}$ or 0.01 for ${ }^{1} \mathrm{H}$ (ref 1 ). Clear circles include proline residues (which cannot be observed because they lack an amide proton), residues for which assignments could not be made due to poor resolution, and residues that do not experience chemical shift perturbation at this level. The bold outline encloses the surface concealed by peroxidase in the top-ranking solution 2 of Table 3 and blue of Figure 5A.

data deviate from simple single site binding. The deviating trend can be adequately accounted for by the binding of a pseudoazurin dimer to some molecules of the peroxidase.
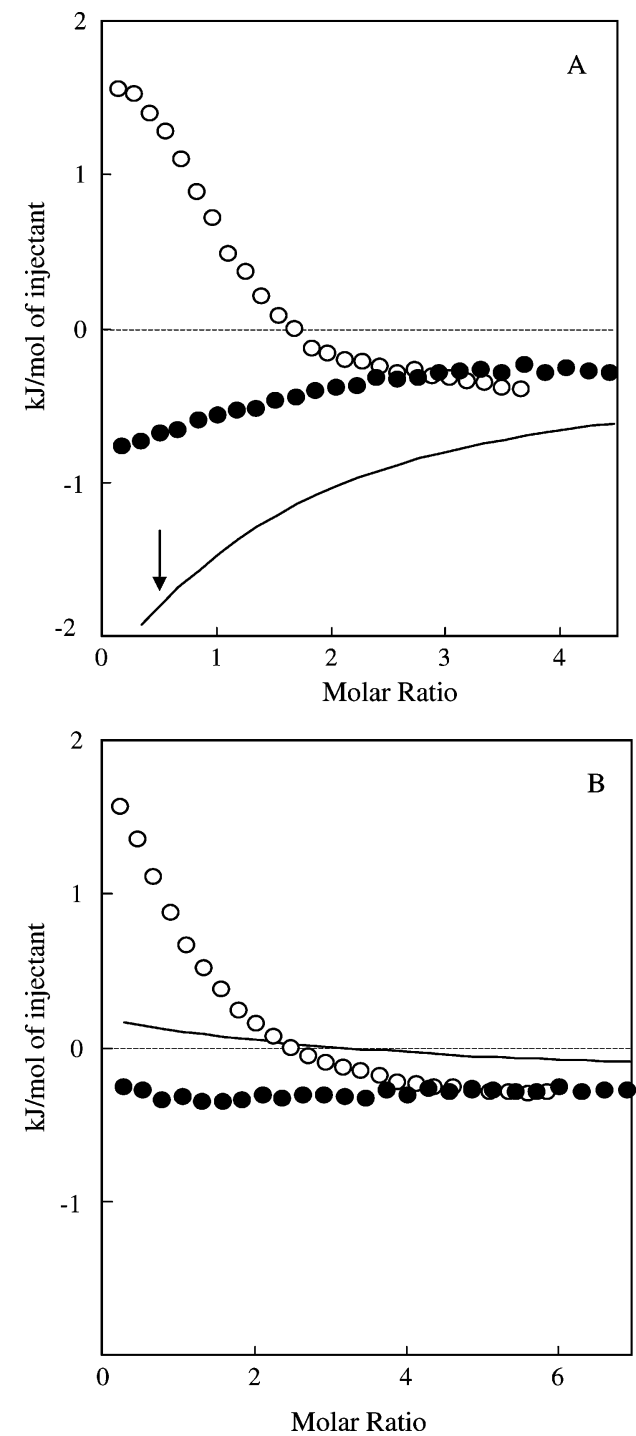

FIGURE 7: Isothermal microcalorimetry of the binding of pseudoazurin or cytochrome $c 550$ to cytochrome $c$ peroxidase in the presence of the other redox partner. Proteins were prepared in 10 $\mathrm{mM}$ cacodylate, $\mathrm{pH} 6.0,10 \mathrm{mM} \mathrm{NaCl}, 2 \mathrm{mM} \mathrm{CaCl}_{2}$ as described in Figure 1. Panel A shows the effect of adding cytochrome $c 550$ $(510 \mu \mathrm{M})$ to cytochrome $c$ peroxidase $(27.2 \mu \mathrm{M}, \mathrm{O})$ or after titration with pseudoazurin $(22.4 \mu \mathrm{M}$ cytochrome $c$ peroxidase, $132.3 \mu \mathrm{M}$ pseudoazurin, ). Panel B shows the effect of adding pseudoazurin $(806 \mu \mathrm{M})$ to cytochrome $c$ peroxidase $(26.8 \mu \mathrm{M}, \bigcirc)$ or after titration with cytochrome $c 550(22.7 \mu \mathrm{M}$ cytochrome $c$ peroxidase, 83.7 $\mu \mathrm{M}$ cytochrome $c 550,0)$ In each case, the microcalorimetry chamber was held at $25^{\circ} \mathrm{C}$, and $10 \mu \mathrm{L}$ increments of titrant were added (after the first increment of $1 \mu \mathrm{L}$ ). Titrations are uncorrected for any dilution effects, and no fit is shown although both primary titrations (open circles in panels A and B) can be corrected for the $y$-axis position and analyzed to give thermodynamic parameters similar to those reported in Table 1 under the same conditions. The solid lines in panels A and B are theoretical curves for a competitive displacement model using the equations of Wang (16) and Sigurskjold (20) and using the $K_{\mathrm{d}}$ and $\Delta H$ values obtained by microcalorimetry (Table 1). These values are $3.7 \mu \mathrm{M}$ and $10.4 \mathrm{~kJ} /$ mol, respectively, for cytochrome $c 550$ and $16.4 \mu \mathrm{M}$ and $16.1 \mathrm{~kJ} /$ mol, respectively, for pseudoazurin. The arrow in panel A indicates the position of the sample calculation shown in Table 2 .

But it could also be accounted for by the presence of a distinct second weak binding site. Again we invoke the known existence of the monomer-dimer equilibrium of the pseudoazurin as support for the simpler explanation that there is a single site and that site can bind the pseudoazurin dimer. 


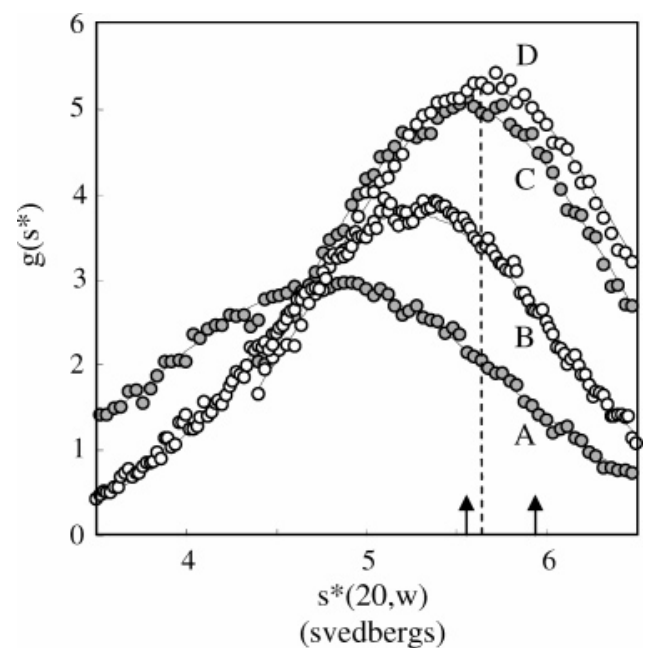

FIGURE 8: Sedimentation velocity ultracentrifugation of cytochrome $c$ peroxidase in the presence of both pseudoazurin and cytochrome $c 550$. Sedimentation velocity experiments were performed in 10 $\mathrm{mM}$ Mes, $10 \mathrm{mM} \mathrm{NaCl}$, and $2 \mathrm{mM} \mathrm{CaCl}_{2}$ at $\mathrm{pH} 6.0,25^{\circ} \mathrm{C}$, and $45000 \mathrm{rpm}$. Paired scans within a set of 10 sequential scans were used to produce a distribution of sedimentation coefficients using the DCDT+ method of Philo (15): (A) $40 \mu \mathrm{M}$ cytochrome $c$ peroxidase (gray circles); (B) $40 \mu \mathrm{M}$ cytochrome $c$ peroxidase and $40 \mu \mathrm{M}$ pseudoazurin (white circles); (C) $40 \mu \mathrm{M}$ cytochrome $c$ peroxidase and $80 \mu \mathrm{M}$ cytochrome $c 550$ (gray circles); (D) $40 \mu \mathrm{M}$ cytochrome $c$ peroxidase, $40 \mu \mathrm{M}$ pseduoazurin, and $80 \mu \mathrm{M}$ cytochrome $c 550$ (white circles). The theoretical fits to the data (solid lines) gave the sedimentation coefficients (A) 4.78, (B) 5.24, (C) 5.54 , and (D) $5.65 \mathrm{~S}$ (broken line). The two arrows indicate the predicted sedimentation coefficients for the two cases of additive $(5.94 \mathrm{~S})$ and competitive $(5.56 \mathrm{~S})$ binding (Table 4).

Table 4: The Effect on the Sedimentation Coefficient $s$ of Adding Binding Proteins to Cytochrome $c$ Peroxidase and the Calculation of Site Occupancies

\begin{tabular}{|c|c|c|c|}
\hline & $\begin{array}{l}\text { exptl } \\
s \\
\text { value }\end{array}$ & site occupancy & $\begin{array}{l}\text { calcd } \\
s \\
\text { value }^{d}\end{array}$ \\
\hline $40 \mu \mathrm{M} \mathrm{CCP}$ & 4.78 & & \\
\hline $\begin{array}{l}40 \mu \mathrm{M} \mathrm{CCP}+ \\
\quad 40 \mu \mathrm{M} \text { pseudoazurin }\end{array}$ & 5.24 & $0.5^{a}$ & \\
\hline $\begin{array}{l}40 \mu \mathrm{M} \mathrm{CCP}+ \\
80 \mu \mathrm{M} \text { cytochrome } c 550\end{array}$ & 5.54 & $0.94^{b}$ & \\
\hline $\begin{array}{l}40 \mu \mathrm{M} \mathrm{CCP}+ \\
40 \mu \mathrm{M} \text { pseudoazurin }+ \\
80 \mu \mathrm{M} \text { cytochrome } c 550\end{array}$ & 5.65 & $\begin{array}{l}\text { (a) additive binding } \\
0.5 \text { pseudoazurin } \\
0.94 \text { cytochrome } c 550 \\
\text { (b) competitive binding }{ }^{c} \\
0.09 \text { pseudoazurin } \\
0.86 \text { cytochrome } c 550\end{array}$ & 5.94 \\
\hline
\end{tabular}

${ }^{a}$ Calculated for a $K_{\mathrm{d}}$ of $20.3 \mu \mathrm{M} .{ }^{b}$ Calculated for a $K_{\mathrm{d}}$ of $2.8 \mu \mathrm{M}$. ${ }^{c}$ Calculated from the competitive binding equations (see Materials and Methods). ${ }^{d}$ The occupancies were used to calculate added $M_{\mathrm{r}}\left(M_{\mathrm{r}}\right.$ cytochrome $c 550=14815 ; M_{\mathrm{r}}$ pseudoazurin $\left.=13405\right)$ using the

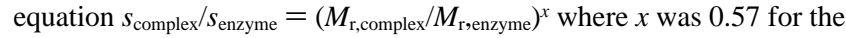
pseudoazurin and 0.47 for the cytochrome $c 550$.

Thus pseudoazurin behaves like cytochrome $c 550$ in having a single binding site on the cytochrome $c$ peroxidase. This is in contrast with the nonphysiological electron donor, horse cytochrome $c$, which binds at two sites with different affinities.

Thermodynamic Parameters for the Binding of Pseudoazurin to Cytochrome c Peroxidase. The thermodynamic parameters for the binding of pseudoazurin resemble those for cytochrome $c 550$ with respect to the large positive enthalpy change offset by an even larger favorable entropy change. That pattern is consistent with an entropically driven process involving release of water molecules from the interface. Where the pseudoazurin differs is in the weaker binding than cytochrome $c 550$ (Table 1) and in the absence of any substantial buffer effect. The latter point may suggest that the proton release observed with cytochrome c550 originated with the cytochrome rather than the peroxidase (although other more complex explanations are possible). Increasing the ionic strength from 0.026 to $0.046 \mathrm{M}$ increased the $K_{\mathrm{d}}$ of pseudoazurin by a factor of 1.7 and had almost no effect on cytochrome $c 550$ (a factor of 1.2). In contrast, the $K_{\mathrm{d}}$ of horse cytochrome $c$ was increased 2.9-fold. Pettigrew et al. (9) related binding to kinetics for the two proteins. The electron-transfer activity of the cytochrome $c 550$ showing little change in this range of ionic strength, whereas the activity of the horse cytochrome $c$ was doubled. This was interpreted to indicate that the horse cytochrome $c$ was trapped in an unproductive orientation on the molecular surface at low ionic strength but increased ionic strength permitted a fluid search for an electron-transfer route. In contrast, the two physiological electron donors seem to find their productive orientation even at low ionic strength. This may be significant in the real world where the bacterium may be exposed to variations in environmental ionic strength with which its periplasm will be in equilibrium. In contrast, the activity of the horse cytochrome $c$ with the bacterial peroxidase has not been "educated" by the evolutionary process, and it is not too surprising that it behaves differently. What the pattern of activity of horse cytochrome $c$ may point to, however, is a physiological capture surface designed to channel physiological electron donors toward a productive orientation for electron transfer. We have postulated a role for the very strong dipole moments of both pseudoazurin and cytochrome $c 550$ in the preorientation of the proteins in such a fluid encounter complex (1).

Pseudoazurin and Cytochrome c550 Share a Single Binding Site on Cytochrome c Peroxidase. We have shown using isothermal microcalorimetry, sedimentation velocity ultracentrifugation, and ${ }^{1} \mathrm{H}$ NMR spectroscopy that pseudoazurin, like its physiological counterpart cytochrome $c 550$, binds to a single site on cytochrome $c$ peroxidase. This is in contrast to the binding of the nonphysiological donor, horse cytochrome $c$, which has two binding sites (9). Indeed, we had previously shown that the peroxidase is capable of binding both horse cytochrome $c$ and cytochrome $c 550$ simultaneously (10), and on the basis of this observation, we had suggested the possibility that pseudoazurin and cytochrome $c 550$ bind simultaneously. There was some physiological appeal to this model in that two electrons are required to restore the active enzyme after oxidation by hydrogen peroxide, and a synchronous delivery of these might have been achieved by a two site model. However, our present analysis of the results of these three techniques shows conclusively that pseudoazurin and cytochrome $c 550$ bind competitively rather than additively. Of course, this may reflect an interference with binding at overlapping sites rather than binding to a single site, but the results of the docking simulation suggest that the two proteins bind at the same point on the molecular surface, close to the exposed edge of the electron-transferring heme of the peroxidase. However, the docking simulation for pseudoazurin was much less clearcut than that for its counterpart cytochrome $c 550$, which gave 
an unambiguous cluster of high-ranking solutions close to the electron-transferring heme (10). Here, it was only with the additional input of the NMR filter that a reasonably clear picture emerged, and even then, there are high-ranking solutions at places on the surface other than the edge of the electron-transferring heme (Figure 4C). Two questions arise from this study. First, why should docking with pseudoazurin be more problematic than that with cytochrome $c 550$ ? One possibility is that the pseudoazurin is an elongated molecule and binds at one end to create a relatively small interface area. The docking algorithm places strong emphasis on the evaluation of the complementarity of the interface and may do less well for a smaller interface. Second, why do we not see solutions that completely satisfy the list of NMR contacts? There is a reasonable correspondence between the pseudoazurin contacts map of ref 1 and the surface concealed by the peroxidase in this paper (Figure 6), but it is not an exact fit. This is not a surprising result if the picture of a relatively fluid electron transfer complex is accepted. If there are several related orientations of the pseudoazurin against the peroxidase, the NMR experiment to determine affected amide groups will reflect this, and no one solution will necessarily satisfy the complete contacts list. For example, the four solutions adjacent to the electron-transferring heme that appear in the final intercept list are all very similar in orientation (Figure 5), yet solutions 2 and 4 satisfy one more contact than solutions 10 and 14 (Table 4).

\section{ACKNOWLEDGMENT}

We are very grateful to Professor V. Fulop and A. Echalier (University of Warwick) for making the coordinates of the activated Paracoccus cytochrome $c$ peroxidase available to us prior to publication.

\section{REFERENCES}

1. Pauleta, S. R., Guerlesquin, F., Goodhew, C. F., Devreese, B., Van Beeumen, J., Pereira, A. S., Moura, I., and Pettigrew, G. W. Biochemistry 43, 11214-11225.

2. Erman, J. E., and Vitello, L. B. (2002) Yeast cytochrome $c$ peroxidase: mechanistic studies via protein engineering, Biochim. Biophys. Acta 1597, 193-200.

3. Hu, W., Van Driesche, G., Devreese, B., Goodhew, C. F., McGinnity, D. F., Saunders, N., Fulop, V., Pettigrew, G. W., and van Beeumen, J. J. (1997) Structural characterisation of Paracoccus denitrificans cytochrome $c$ peroxidase and assignment of the low and high potential heme sites, Biochemistry 36, 79587966.

4. Fülöp, V., Ridout, C. J., Greenwood, C., and Hajdu, J. (1995) Crystal structure of the di-haem cytochrome $c$ peroxidase from Pseudomonas aeruginosa, Structure 3, 1225-1233.

5. Shimizu, H., Schuller, D. J., Lanzilotta, W. N., Sundaramoorthy, M., Arciero, D. M., Hooper, A. B., and Poulos, T. L. (2001) Crystal structure of Nitrosomonas europaea cytochrome $c$ per- oxidase and the structural basis for ligand switching in bacterial di-heme peroxidases, Biochemistry 40, 13483-13490.

6. Foote, N., Peterson, J., Gadsby, P. M. A., Greenwood, C., and Thomson, A. J. (1985) Redox-linked spin-state changes in the di-haem cytochrome $c$-551 peroxidase from Pseudomonas aeruginosa, Biochem. J. 230, 227-237.

7. Ellfolk, N., Rönnberg, M., Aasa, R., Andreasson, L. E., and Vänngard, T. (1983) Properties and function of the two hemes in Pseudomonas cytochrome $c$ peroxidase, Biochim. Biophys. Acta $743,23-30$.

8. Pettigrew, G. W., Prazeres, S., Costa, C., Palma, N., Krippahl, L., Moura I., and Moura, J. J. (1999) The structure of an electrontransfer complex containing a cytochrome $c$ and a peroxidase. $J$. Biol. Chem. 274, 11383-11389.

9. Pettigrew, G. W., Goodhew, C. F., Cooper, A., Nutley, M., Jumel, K., and Harding, S. E. (2003) Electron-transfer complexes of cytochrome $c$ peroxidase from Paracoccus denitrificans, Biochemistry 42, 2046-2055.

10. Pettigrew, G. W., Pauleta S. R., Goodhew, C. F., Cooper, A., Nutley, M., Jumel, K., Harding, S. E., Costa C., Krippahl, L., and Moura, J. J. (2003) Electron-transfer complexes of cytochrome $c$ peroxidase from Paracoccus denitrificans containing more than one cytochrome, Biochemistry 42, 11968-11981.

11. Moir, J. W., Baratta, D., Richardson, D. J., and Ferguson, S. J. (1993) The purification of a cd1-type nitrite reductase from, and the absence of a copper-type nitrite reductase from, the aerobic denitrifier Thiosphaera pantotropha; the role of pseudoazurin as an electron donor, Eur. J. Biochem. 212, 377-385.

12. Koppenol, W. H., Rush, J. D., Mills, J. D., and Margoliash, E. (1991) The dipole moment of cytochrome c, Mol. Biol. Evol. 8, 545-558.

13. Goodhew, C. F., Wilson, I. B., Hunter, D. J., and Pettigrew, G. W. (1990) The cellular location and specificity of bacterial cytochrome $c$ peroxidases, Biochem. J. 271, 707-712.

14. Laue, T. M., Shah, B. D., Ridheway, T. M., and Pelletier, S. L. (1992) Computer-aided interpretation of sedimentation data for proteins, in Analytical ultracentrifugation in Biochemistry and Polymer Science (Harding, S. E., Rowe, A. J., and Horton, J. C., Eds.) pp 90-125, Royal Society of Chemistry, London.

15. Philo, J. S. (2001) A method for directly fitting the time derivative of sedimentation velocity data and an alternative algorithm for calculating sedimentation coefficient distribution functions, Anal. Biochem. 279, 151-163.

16. Wang, Z.-X. (1995) An exact mathematical expression for describing competitive binding of two different ligands to a protein molecule, FEBS Lett. 360, 111-114.

17. Palma, P. N., Krippahl, L., Wampler, J. E., and Moura, J. J. G. (2000) BiGGER - a new (soft) docking algorithm for predicting protein interactions, Proteins 39 (4), 372-384.

18. Williams, P. A., Fulop, V., Leung, Y. C., Chan, C., Moir, J. W., Howlett, G., Ferguson, S. J., Radford, S. E., and Hajdu, J. (1995) Pseudospecific docking surfaces on electron-transfer proteins as illustrated by pseudoazurin, cytochrome $c 550$ and cytochrome cd 1 nitrite reductase, Nat. Struct. Biol. 2, 975-982.

19. Smidsrod, O., and Andreson, I.-L., (1979) Biopolymer Kjemi, Tapir Press, Trondheim, Norway.

20. Sigurskjold, B. W. (2000) Exact analysis of competition ligand binding by displacement isothermal titration calorimetry, Anal. Biochem. 277, 260-266.

21. Leesch, V. W., Bujous, J., Mauk, A. G., and Hoffman, B. M. (2000) Cytochrome $c$ peroxidase-cytochrome $c$ complex: locating the second binding domain on cytochrome $c$ peroxidase with sitedirected mutagenesis, Biochemistry 39, 10132-10139.

BI0485833 